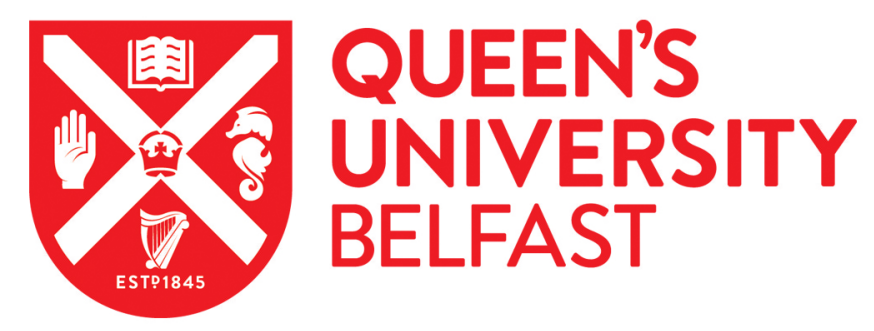

\title{
Temporal concepts and episodic memory: A response to Hoerl
}

McCormack, T. (1999). Temporal concepts and episodic memory: A response to Hoerl. Mind \& Language, 14(2), 252-262.

Published in:

Mind \& Language

Document Version:

Publisher's PDF, also known as Version of record

Queen's University Belfast - Research Portal:

Link to publication record in Queen's University Belfast Research Portal

\section{General rights}

Copyright for the publications made accessible via the Queen's University Belfast Research Portal is retained by the author(s) and / or other copyright owners and it is a condition of accessing these publications that users recognise and abide by the legal requirements associated with these rights.

Take down policy

The Research Portal is Queen's institutional repository that provides access to Queen's research output. Every effort has been made to ensure that content in the Research Portal does not infringe any person's rights, or applicable UK laws. If you discover content in the Research Portal that you believe breaches copyright or violates any law, please contact openaccess@qub.ac.uk. 


\title{
Temporal Concepts and Episodic Memory: A Response to Hoerl
}

\author{
TERESA McCORMACK
}

\begin{abstract}
Hoerl claims that episodic memory is necessary for a concept of the past, and that we should consider some severely amnesic patients as lacking such a concept. I question whether this description of such patients is plausible, and whether it helps us understand lack of insight in amnesia. I finish by arguing that Hoerl's analysis of what constitutes a concept of the past raises interesting developmental issues.
\end{abstract}

The aim of Hoerl's paper is to explore the relationship between episodic memory and temporal concepts. The first sections of the paper show that in ascribing a concept of the past, it is not enough to merely demonstrate that someone's actions or mental states involve memory retrieval or have as a point of fact been causally affected by a past experience. The second half of the paper develops the suggestion that a particular kind of memory, episodic memory, is necessary for a concept of the past. The basic argument is that it is in remembering what one did at particular times in the past that one grasps the irrevocable nature of one's actions. Such a grasp is at least part of what is involved in understanding the unrepeatability of episodes. This understanding of the uniqueness of points of time is thought to be at the core of our concept of the past (see Campbell, 1994, for the relevant distinction between temporal orientation with respect to particular times and with respect to phase). Here, I focus on how the claims of the paper are related to psychological research.

\section{Amnesia and Temporal Concepts}

If Hoerl's claims are correct, then temporal concepts should only be ascribed to those with at least some episodic memories. Complete loss of episodic

\footnotetext{
The author is supported by a grant from the Medical Research Council (G9608199). I am grateful to the members of the HRB Consciousness and Self Consciousness Project at the University of Warwick (in particular, Christoph Hoerl, Naomi Eilan, and Johannes Roessler) for invaluable discussion of the issues addressed here.

Address for correspondence: Department of Psychology, University of Warwick, Coventry, UK, CV4 7AL.

Email: T.McCormack@warwick.ac.uk
} 
memory would be expected to be accompanied by loss of temporal concepts. Thus, it may be useful to consider amnesic cases in the light of such a prediction. However, as is pointed out in the paper, in many cases of amnesia, loss of episodic memory is not total. Further, some patients manifest their intact grasp of a concept of the past in their insight into their own condition. They report experiencing a sense of loss that there are periods of their personal past that are inaccessible to them in memory. In taking steps to compensate for their memory difficulties, they demonstrate an understanding that current experiences will, at some point in the future, be past experiences. Indeed, such insight behaviours are the most obvious to point to in demonstrating intact temporal understanding in such patients. However, an important issue raised by Hoerl's paper is whether the reverse could be true, whether a lack of insight into the amnesic condition should ever be interpreted in terms of a loss of temporal concepts. Hoerl argues that some severely amnesic patients 'cannot have an appropriate understanding of the situation they are in. They lack the conceptual resources for capturing what is wrong with them; in particular they do not have an adequate concept of time'.

One of the difficulties with this interpretation is that it predicts that lack of insight should be associated with severity of amnesia, since loss of the relevant conceptual resources is thought to be a consequence of loss of episodic memory. A lack of insight has been found in many neuropsychological disorders (see Prigatano and Schacter, 1991), and in general the relationship between severity of impairment and level of insight into that impairment is not straightforward. ${ }^{1}$ With respect to amnesia, there are good reasons to believe that lack of insight into memory symptoms is associated with frontal damage rather than severity of memory loss (Schacter, 1991). For example, those amnesics who show lack of awareness tend to be either those with Korsakoff's Syndrome, which is associated with frontal lobe pathology, or patients who have suffered head injuries which have damaged the frontal lobes as well as memory regions (McGlynn and Schacter, 1989). Patients with restricted temporal lobe pathology typically have severe memory loss, but nevertheless tend to show at least some insight into their condition. Thus, Schacter (1991) has argued that lack of insight in amnesia is primarily due to a failure of executive functions which monitor and evaluate memory performance and failure. Therefore, there is something like a double dissociation here: lack of insight is found in patients who do not necessarily have the most severe episodic memory loss (but have frontal damage), and patients who have very severe episodic memory loss do not necessarily show lack of insight. Although these considerations may make Hoerl's interpretation

1 I use the term 'level of insight', since patients may vary in the consistency with which they acknowledge their disorder, and whether they show insight can depend on how such awareness is assessed. Further, it is has been suggested that even when patients verbally deny their deficit, their behaviour may suggest knowledge of it (Prigatano and Schacter, 1991). 
less compelling, he could admit that lack of insight in most cases is not simply a consequence of episodic memory impairment, but still maintain that there are at least some cases of unawareness for which his interpretation holds.

\subsection{Episodic Memory and Lack of Insight}

If we set aside for the moment the likelihood that, for the majority of cases, unawareness of amnesia is related to frontal pathology, it is possible to distinguish between two ways in which severe episodic memory loss by itself could cause lack of insight. Firstly, one intuitive possibility is that such patients cannot remember over time that they have a memory impairment, or do not have the information available to them to reach an understanding of their condition. For example, Schacter (1983) reported that a densely amnesic patient tended to only remember the severity of his condition immediately after he had experienced a salient instance of memory failure; otherwise he claimed to have near-normal memory. Van der Linden and Coyette (1995) noted that their patient AC rates his memory abilities as within the normal range and is 'completely unable to recall any specific episodes of memory dysfunction' (p. 70), despite having experienced severe amnesia for several years. Such a profound inability to remember one's previous memory failures must hamper the dawning of insight. Nevertheless, over a period of time and after repeated exposure to memory failures, combined with repeated attempts by others to demonstrate to the patient his or her deficit, it seems that it is possible to learn about one's amnesia (Schacter, 1991).

However, according to Hoerl's explanation, there may be some patients for whom such dawning of insight could never occur. He argues that there are some patients who lack the concepts needed to understand their condition. According to his explanation, such patients cannot have a conception of a personal past which is unknown to them, because they do not have a concept of the past. Why should we opt for the more radical explanation in terms of a loss of temporal concepts? Hoerl argues that not all kinds of temporal thought need involve a concept of the past, by distinguishing between two ways of locating events familiar from the philosophical literature. Possessing some kinds of temporal information about events may involve locating them only with respect to the so-called B-series, the series of positions running from earlier to later (often captured by temporal terms such as 'before' or 'after'). This may fall short of locating events with respect to the A-series, which places events with respect to one's current temporal perspective (e.g. by using terms such as 'now' or 'a long time ago'). For example, one could give the date of an event without specifying whether it has yet to happen, or one could describe the order in which a series of events usually happens without in addition locating such a series at any particular point in the past, present or future. A full-blown concept of time involves locating events with respect to the A-series as well as the B-series.

Thus, in examining the temporal understanding of severely amnesic 
patients we can ask whether there is evidence that they can combine both ways of locating events. Since some semantic knowledge is intact, the ability to describe the sequential temporal relations of at least some events remains. For example, Hoerl refers to the patient PS described by McCarthy and Hodges (1995), who in formal testing is incapable of recalling any [original italics] specific episodes' (p. 35) and who 'lacks insight into his deficits and denies any cognitive impairment' (p. 33). Nevertheless, McCarthy and Hodges reported that PS is capable of placing famous people (although not famous events) in an appropriate date order, indicating the use of temporal information described by the B-series. Further, patients may explicitly temporally relate their current circumstances to specific previous or future times: for example, PS will claim that he has just got back on leave from a term of Navy service (in fact, he served several decades earlier during the war), and another patient, mentioned by Hoerl, Clive Wearing, will claim that he has only just woken up after a period of unconsciousness. These latter kinds of reports are striking in that, although the patients' statements are factually inaccurate, they seem to involve more than locating events with respect to the B-series: they seem to involve something like a perspective on time.

\subsection{Impaired Reasoning?}

In the face of what looks like competent use of temporal language, why might the claim that such patients lack a concept of the past have any plausibility? One line of argument here might be to query whether what looks like competent use of temporal language really is underpinned by an understanding of the past, given that some patients will repeatedly fail to accept evidence which contradicts their false statements about the past. For example, McCarthy and Hodges (1995) reported that PS, who appears not to remember any episodes, at least from the period of time elapsed since his wartime Navy service, 'would agree that being on active Navy service when over sixty is highly implausible, but his memory "illusion" was more compelling than was rational thought' (p.34). Such denials persist in the face of overwhelming physical evidence to the contrary, and could be interpreted as irrational. However, there are two things that can be said here. Firstly, perhaps one should be particularly wary in cases of failure of insight into severe amnesia to conclude that reasoning is irrational. Secondly, even if we want to argue that there is something irrational about such reasoning, it is questionable whether this is best captured by assuming a loss of a concept of the past. With regard to the first point, even in everyday life when one is faced with a choice between physical evidence of what happened recently, and contrary information that is yielded by memory, under some circumstances it may be rational to question the evidence. This may involve raising questions about the causal sequences of events that led to the physical evidence. It becomes more difficult to judge pathological cases in which memory does not yield a contrary version of events, but rather, simply no information at all about one's recent experiences. In such cases, the choice may 
be between accepting the physical evidence of what has actually happened, or assuming that one's failure to remember means that such recent events did not occur. In the circumstances that have been described in the literature, in which amnesics are confronted with clear evidence of previous unremembered events, perhaps questioning such evidence does amount to a denial that normal causal relations in the world hold. However, it should be again borne in mind that the patient may be simply unable to recall any previous instances of memory failure: to some patients, it may be as if they are experiencing the conflict between the contents (or the lack of) of their recent memories and the physical evidence for the first time. Further, there is also no reason to believe that patients have a global problem in reasoning about the causal relations that obtain between events, outside of those particular event sequences which conflict with their memories. For example, such patients may be able to give causal explanations for other sorts of physical phenomena, and show in their behaviour and goal-setting an awareness of the causal relations that obtain in their surroundings.

However, there are some amnesic cases in which the denial of physical evidence does seem to be irrational. For example, Downes and Mayes (1995) have described a confabulating amnesic patient, WF, who regularly insists that he remembers having had a row with his father the previous evening. ${ }^{2}$ When presented with clear evidence that his father died some time earlier, he concludes that his father must have come back to life. In such cases, choosing one's memories over physical evidence does indeed appear to have a delusional quality that might make us uncertain as to whether the patient really understands what it is for something to be in the past (see Downes and Mayes for further discussion of why WF should be considered to have delusional rather than simply false beliefs). However, even if one wishes to maintain that in these cases such reasoning is irrational, it is far from clear that what has gone wrong amounts to a loss of a concept of the past. Rather, the intuition is that it is precisely because the patient is prepared to engage in a debate over what has happened recently that we should accept that he understands what it is for something to be in the past. It seems to me that it is only because PS has an (albeit incorrect) opinion on what his circumstances were in the recent past (i.e. he thinks he has recently returned from Navy service) that he is prepared to deny the clinician's version of events.

Further, insofar as properly understanding the nature of memory requires a concept of the past, there is additional evidence that this concept is intact. Schacter (1991) has described a severely amnesic patient who incorrectly rates his memory to be as good as his wife's, but nevertheless knows how memory usually functions: for example, he can correctly predict that it becomes increasingly difficult to remember things after a delay. Similarly, although some patients may be unable to ascribe the condition of amnesia

2 Again, this patient does not have restricted temporal lobe lesions; he shows signs of frontal damage. 
to themselves, they seem to understand the concept and could potentially apply it to someone else. It is difficult to interpret the distress of Clive Wearing when the possibility that he is amnesic is suggested to him (Wilson, Baddeley, and Kapur, 1995) unless one accepts that he understands the profound implications of such a diagnosis.

It may well be the case that for some kinds of failure of insight in neuropsychological cases, interpreting the patients' problems in terms of a loss of a type of reasoning or a particular concept helps make sense of a range of otherwise puzzling behaviours. However, the particular account given here by Hoerl in terms of loss of temporal concept does not seem to illuminate the difficulties of severely amnesic patients. Rather, it requires a radical reinterpretation of their verbal behaviour. It also lacks force given the body of evidence that suggests persistent lack of insight in amnesia is related to executive dysfunction rather than simply a consequence of amnesia. More generally, from the point of view of providing an elucidation of the relationship between episodic memory and temporal concepts, it has not been established that an appeal to evidence from actual amnesic cases is useful. Of course, it may well be that the kinds of pure cases that would be crucial in demonstrating such a relationship do not exist, or, as Hoerl points out, such cases could be so severely cognitively impaired that a diagnosis of complete memory loss would never be established.

\section{Episodic Memory Development and Temporal Concepts}

Despite these points, both the consideration of the relationship between episodic memory and temporal concepts that Hoerl provides, and his analysis of what it is to have a concept of the past, are greatly needed. Such questions have been largely neglected, at least by psychologists (see Campbell, 1994, 1997, for further analyses of the relation between memory and temporal concepts). They should be of particular relevance to developmental psychologists: given the fundamental role that temporal concepts play in our thinking and reasoning, it is extremely important to give an account of their emergence in development. It should be noted, though, that Hoerl explicitly does not intend for his claim regarding the relationship between episodic memory and temporal concepts to be interpreted as a causal development claim. He points out that he is not trying to provide a reductive analysis of possession of a concept of the past in terms of possession of episodic memory; if one can remember episodically, then one already has the requisite notion of the uniqueness of points of time. Nevertheless, his analysis of what constitutes having such a concept may be useful to developmentalists.

Most accounts of the development of temporal concepts have taken as their starting point Piagetian work on the development of a grasp of the relationship between time, speed and distance (Levin, 1992). However, as Hoerl's paper makes clear, there are more fundamental aspects of temporal reasoning than reasoning about such mathematical relations, although they may be difficult to study experimentally (see Nelson, 1996, ch. 9). 
Thus, one key issue is whether young children, rather than amnesic patients, should be characterized as not yet understanding the unrepeatability of episodes and therefore lacking a concept of the past. It is plausible to suggest that to learn effectively about the world, infants and young children need not represent their experiences as unique episodes. Rather, as Hoerl suggests, insofar as learning about one's environment is useful because it allows one to make predictions, what matters is that one learns the relative order of events that comprise recurrent sequences, rather than the particular locations of events in time (Friedman, 1993). In other words, it is useful to know what usually happens (Nelson, 1990), and it is likely that there are basic temporal mechanisms which allow both humans and animals to extract such temporal structure from their experience and use it to guide their behaviour (Brown and Vousden, 1998; Gallistel, 1990). Developmental memory researchers have used a variety of paradigms to demonstrate the efficiency with which young children will learn sequences of events, with learning sometimes occurring after a single exposure to the sequence (e.g. Bauer and Mandler, 1989; Fivush, Hudson, and Nelson, 1984). ${ }^{3}$ If representing potentially recurrent sequences is the developmental primitive, then when and how does the child develop the concept of unique episodes (and thus of the past)?

\subsection{Perspectival and Nonperspectival Temporal Representations}

If Hoerl is correct, to answer such questions we need to consider the ways children have of temporally locating events. A mature concept of time allows events to be located with respect to both the A-series and the B-series: it has both perspectival and nonperspectival ingredients. Although the distinction between perspectival and nonperspectival representations has featured strongly in developmental research on spatial concepts, it has not guided research on children's time concepts (although see Miller and Johnson-Laird, 1976, for a discussion of children's temporal understanding in terms of the A- and B-series). Nevertheless, it may provide a useful way of considering the emergence of basic temporal concepts. Thus, Hoerl's paper implies that to be said to have a concept of the past, the child needs to combine extracting the relative order of events with locating such event sequences with respect to her current temporal perspective.

However, Hoerl and I have argued elsewhere (McCormack and Hoerl, 1999), that the most primitive kinds of representations which have both perspectival and nonperspectival ingredients need not yet involve a mature concept of the past. The mature use of tense by definition involves combining information described by both the A-series and the B-series (Reichenbach,

\footnotetext{
Some memory researchers might argue that the fact that infants can remember a sequence after a single exposure indicates that they have episodic memory. However, at least according to the way the term episodic memory is used by Hoerl, one's memories could stem from a single learning experience without one remembering episodically.
} 
1947). Interestingly, existing theories of the development of tense can be interpreted as differing in their characterization of the perspectival nature of children's early temporal representations. In particular, there is some debate over what kind of temporal understanding underpins children's first use of the past tense. On some accounts, first uses of the past tense already mark the appropriate A-series relation, the relation between the child's current temporal perspective (i.e. 'now', the speech time) and the previous time at which an event occurred ('then', the event time) (e.g. Weist, 1989, provides such an account in detail). Alternatively, according to the defective tense hypothesis, early uses of the past tense are actually marking something like the fact that an action or event sequence has been completed (more technically, aspect rather than tense is being marked; Antinucci and Miller, 1976; Bloom and Harner, 1989). Although there is considerable debate as to whether or not the evidence supports this hypothesis, the important point for present purposes is that it at least suggests a way in which temporal thought could, in some primitive sense, be perspectival without yet involving A-series relations. ${ }^{4}$ The kind of primitive temporal thought suggested by this hypothesis can be described as event-based (McCormack and Hoerl, 1999), since the perspective involved is a perspective on whether events are ongoing or completed. Being oriented to the status of events in this way can be contrasted with being able to think of them as located in the present, past or future. Importantly, this kind of primitive temporal thought, although it may have both perspectival and nonperspectival ingredients, need not involve a concept of the past: being able to think of an event as completed need not yet involve locating it at a unique point in the past. The knowledge involved may be of the kind Hoerl describes as 'knowledge in which events figure only in virtue of the general repeatable types under which they fall'.

\subsection{The Irrevocability of Actions}

What more might be needed for a concept of the past? Hoerl argues that what is required is an understanding of the irrevocability of events-in particular, an understanding that one's actions can make an irreversible difference to the way the world is. It is difficult to see how such understanding could emerge without reflection on the relationship between remembered actions and one's current circumstances. In other words, part of what is involved here is a particular kind of understanding of causality. Campbell (1994) has made the relevant distinction between a purely practical and a reflective understanding of causality. A practical grasp of causality allows a sensitivity to the causal structure of the temporally extended world to be manifest in action. It is possible to act effectively without a reflective grasp of causality, through a process like detecting correlations between different

4 In fact, Hoerl and I have argued for a modified version of the defective tense hypothesis which does not have the same empirical entailments as the original hypothesis. 
actions and events. By contrast, a reflective understanding of causality cannot be reduced to this kind of practical understanding. Such reflective understanding would allow, for example, one to give causal explanations for one's circumstances or causal reasons for one's actions. It is the latter kind of understanding that is involved in grasping the unrepeatability of actions. Early in development, children show in their behaviour a sensitivity to the casual structure of the world: for example, memory for an observed sequence of events, as measured in studies of deferred imitation, is greatly facilitated if there are casual relations between the events (Bauer and Fivush, 1992). However, it may of course be a further developmental step from sensitivity to causal relations to the ability to reflect on such relations. Hoerl argues that such reflective understanding is manifest in a fundamental way when, in remembering episodically, one grasps that one's previous actions have constrained the current possibilities for action.

These considerations provide some pointers for interpreting existing experimental work. For example, a number of recent studies have explored whether children understand the relationship between previous events and their current circumstances. Typically, children are shown a videotape of an event that happened earlier, of which they were previously unaware, and their current response to that earlier event is observed (Povinelli, Landau and Perilloux, 1996; Zelazo, Sommerville and Nichols, in press). The findings could be interpreted as showing that 3-year-olds find it difficult to reason about the relations between what happened earlier and the current state of affairs (although the tasks do measure additional abilities, such as an understanding of the representational media involved). However, it seems we can still query whether such tasks should be interpreted as assessing reasoning about unique episodes: it may be possible to succeed by simply being sensitive to regularities and behaving appropriately (along the lines of 'when $x$ happens, then y usually happens, therefore do this'). ${ }^{5}$ If Hoerl is correct, then if what we are concerned with is examining children's concepts of time, we need to use paradigms which explore children's understanding of the irrevocable consequences of their actions.

\section{Conclusions}

Where does this leave the relationship between episodic memory and temporal concepts? I think a strong case has yet to be made for studying amnesic patients in the context of establishing a relationship between episodic memory and temporal concepts. However, I agree with Hoerl that one cannot ascribe a concept of the past simply by demonstrating that someone can

5 In particular, it is not clear that to pass such tasks one need be able to think of the particular time at which the previous event happened independently of the actual event sequence which has unfolded. It is in this sense that what has been termed 'event-based' temporal though may be sufficient for success. 
remember facts, or even that someone has memories which have as a point of fact been caused by a single experience. The fundamental question is whether the rememberer is capable of thinking of particular past times. From a consideration of how possessing a concept of the past is in play in remembering episodically, it becomes clear that questions regarding the emergence of episodic memory in childhood cannot, in the end, be separated from questions relating to children's concepts of time.

Many questions remain as to how such a conception of the past emerges developmentally. Although it may be useful to draw on developmental linguistic research to try to trace how children's temporal understanding changes, an obvious question is how such understanding interacts with the acquisition of temporal language (Nelson, 1996). Further, one can ask whether particular kinds of social experiences are crucial in developing the grasp of the irrevocability of action that Hoerl pinpoints as demonstrating thought of particular times. What is clear is that being able to think of one's past in terms of unique episodes is part of what constitutes an objective conception of time, and how such a conception emerges is a fundamental developmental question.

Department of Psychology University of Warwick

\section{References}

Antinucci, F. and Miller, R. 1976: How Children Talk About What Happened. Journal of Child Language, 3, 167-89.

Bauer, P.J. and Fivush, R. 1992: Constructing Event Representations: Building on a Foundation of Variations and Enabling Relations. Cognitive Development, 7, 381-401.

Bauer, P.J. and Mandler, J.M. 1989: One Thing Follows Another: Effects of Temporal Structure on 1- to 2-year-olds' Recall of Events. Developmental Psychology, 25, 197-206.

Bloom, L. and Harner, L. 1989: On the Developmental Contour of Child Language: A Reply to Smith and Weist. Journal of Child Language, 16, 207-16.

Brown, G.D.A. and Vousden, J.I. 1998: Adaptive Analysis of Sequential Behaviour: Oscillators as Rational Mechanisms. In M. Oaksford and N. Chater (eds), Rational Models of Cognition. Oxford University Press.

Campbell, J. 1994: Past, Space, and Self. Cambridge, MA: MIT Press.

Campbell, J. 1997: The Structure of Time in Autobiographical Memory. European Journal of Philosophy, 5, 105-18.

Downes, J.J. and Mayes, A.R. 1995: How Bad Memories Can Sometimes Lead to Fantastic Beliefs and Strange Visions. In R. Campbell and M.A. Conway (eds), Broken Memories: Case Studies in Memory Impairment. Oxford: Blackwell.

Fivush, R., Hudson, J.A. and Nelson, K. 1984: Children's Long-term Memory for a Novel Event: An Exploratory Study. Merrill-Palmer Quarterly, 30, 303-16.

Friedman, W.J. 1993: Memory for the Time of Past Events. Psychological Bulletin, $113,44-66$. 
Gallistel, C.R. 1990: The Organization of Learning. Cambridge, MA: MIT Press.

Levin, I. 1992: The Development of the Concept of Time in Children: An Integrative Model. In F. Macar, V. Pouthas and W.J. Friedman (eds), Time, Action, and Cognition: Towards Bridging the Gap. Dordrecht: Kluwer.

McCarthy, R.A. and Hodges, J.R. 1995: Trapped in Time: Profound Autobiographical Memory Loss Following a Thalamic Stroke. In R. Campbell and M.A. Conway (eds), Broken Memories: Case Studies in Memory Impairment. Oxford: Blackwell.

McCormack, T. and Hoerl, C. 1999: Memory and Temporal Perspective: The Role of Temporal Frameworks in Memory Development. Developmental Review, 19, 154-182.

McGlynn, S.M. and Schacter, D.L. 1989: Unawareness of Deficits in Neuropsychological Syndromes. Journal of Clinical and Experimental Neuropsychology, 11, 143-205.

Miller, G.A. and Johnson-Laird, P.N. 1976: Language and Perception. Cambridge, MA: Harvard University Press.

Nelson, K. 1990: Remembering, Forgetting and Childhood Amnesia. In R. Fivush and J.A. Hudson (eds), Knowing and Remembering in Young Children. Cambridge University Press.

Nelson, K. 1996: Language in Cognitive Development: The Emergence of the Mediated Mind. Cambridge University Press.

Povinelli, D.J., Landau, K.R. and Perilloux, H.K. 1996: Self-Recognition in Young Children using Delayed versus Live Feedback: Evidence of a Developmental Asynchrony. Child Development, 67, 1540-54.

Prigatano, G.P., Schacter, D.L. 1991: Awareness of Deficit After Brain Injury: Clinical and Theoretical Issues. Oxford University Press.

Reichenbach, H. 1947: Elements of Symbolic Logic. New York: Macmillan.

Schacter, D.L. 1983: Amnesia Observed: Remembering and Forgetting in a Natural Environment. Journal of Abnormal Psychology, 92, 236-42.

Schacter, D.L. 1991: Unawareness of Deficit and Unawareness of Knowledge in Patients with Memory Disorders. In G.P. Prigatano and D.L. Schacter (eds), Awareness of Deficit After Brain Injury: Clinical and Theoretical Issues. Oxford University Press.

Van der Linden, M. and Coyette, F. 1995: Acquisition of Word-Processing Knowledge in an Amnesic Patient: Implications for Theory and Rehabilitation. In R. Campbell and M.A. Conway (eds), Broken Memories: Case Studies in Memory Impairment. Oxford: Blackwell.

Weist, R.M. 1989: Time Concepts in Language and Thought: Filling the Piagetian Void from Two to Five years. In I. Levin and D. Zakay (eds), Time and Human Cognition: A Life-Span Perspective. Amsterdam: Elsevier.

Wilson, B.A., Baddeley, A.D., Kapur, N. 1995: Dense Amnesia in a Professional Musician Following Herpes Simplex Virus Encephalitis. Journal of Clinical and Experimental Neuropsychology, 17, 668-81.

Zelazo, P.D., Sommerville, J. and Nichols, S. in press: Age-related Changes in Children's Use of External Representations. Developmental Psychology. 